\title{
Korrespondenzen.
}

\section{Deutschfeindlichkeit in Australien.}

Von einem deutschen Arzte Australiens erhalten wir folgende Zuschrift:

Seit dem 1. Juli letzten Jahres ließ ich durch einen Freund auf lhre" geschätzte Wochenschrift abonnieren. Bald darauf wurde bekannt gegeben, daß die australische Commonwealth-Regierung die Einfuhr de utscher Zeitungen und Bücher verboten habe. Dessenungeachtet aber traf 1 hr Fachblatt, mit Ausnahme einiger Nummern, hier regelmäßig ein. Einige meiner Bekannten, denen von Deutschland wöchentlich Zeitschriften zugesandt wurden, erhielten sie nie, so sah ich mich denn gezwungen, thre Wochenschrift vom 1. Januar ab aufzugeben. - Schon während des Krieges wurden Schiritte hier unternommen, alles Deutschtum auszurotten, und niemand hat sich in dieser Beziehung stärker breit gemacht als die British Medical Association. Nicht allein schlob sie alle in Deutschland geborenen und diplomierten, hier praktizierenden Aerztè von ihrer Mitgliedschaft aus, sondern sie versuchte in jeder Weise, da $\beta$ alle internierten. Aerzte vom Aerzteregister gestrichen und deportiert werden sollten. Hier in Neusüdwales ist es ihr dadurch, daß eine neue, weniger ausgesprochen deutschfeindliche $\mathrm{Re}$ gierung ans Ruder kam, nicht gelungen, und so dürfen denn wir noch weiter praktizieren. In Queensland dagegen wurde Dr. W. noch weiter praktizieren. In Queensland dagegen wurde Dr. W.
Witt rocks Name vom Register entfernt (ohne daB ein besonderes Gesetz diesen Schritt rechtsgültig gemacht hätte), und sein Antrag um Registration ist zweimal abgelehnt worden, ohne für diese Ablehnung irgendwelche Gründe anzugeben. -- Australien bietet also kein Feld für deutsche Aerzte, die etwa auszuwandern beabsichtigen, denn nicht allein ist durch australisches Gesetz für 5 Jahre hinaus eine Einwanderung Deutscher und Oesterreicher verboten, sondern einige Einzelstaaten haben auch während des Krieges ihre Medizinalgesetze so ungeändert, daß in Zukunft deutsche und österreichische Diplome nicht mehr anerkannt werden.

Folgende Aerzte waren während des Krieges interniert in Austratien: Dr. W. Wittrock, Dr. Eugen Hirschfeld (deportiert), Dr. Lohde (deportiert), sämtlich in Queensland, Dr. Setzka (auf eigenen Antrag repatriert) und Dr. Finselbach in Neusüdwales." 